\title{
Adverse Effects of Imipramine are Increased by Interaction with ASA in Depressed Patients
}

Because protein binding is a process that can be changed by the presence of other drugs with similar or greater affinity for proteins than the original compound, this causes a greater concentration of the free drug, while potentializing adverse effects, the most important factor responsible for noncompliance (Demyttenaere 1997; Fincke et al. 1998). The purpose of this study was to measure the binding of imipramine to plasma proteins when administered simultaneously with acetyl salicylic acid (ASA). Such interaction would be more clearly defined using clinical assessment parameters in patients treated with imipramine, who additionally need the second drug. The study was carried out in 20 clinically diagnosed depressed patients $(16 \mathrm{~F}, 4 \mathrm{M}$, average age $38.3 \pm 13.3$ years and weight $63.8 \pm 9.0 \mathrm{~kg}$ ) to which imipramine (Tofranil) was administered at doses of $75 \mathrm{mg}$ every $12 \mathrm{~h}$. Informed consent was obtained for all patients before the study.

After the first 3 days, while fasting, 6-ml blood samples were taken from the patients and processed. The following were measured: (1) total concentration of the drug in plasma; (2) fraction of imipramine bound to plasma proteins as reported in Juárez and Jung (1986), and protein levels, as indicators of the protein state in the patients studied. Before taking the sample, each patient's clinical state was assessed using a questionnaire on the possible effects a patient reported, recording the time when the effect arose, its duration, and its severity. This questionnaire was previously validated by the Mental Health Division, Department of the Faculty of Medicine (UNAM). After this first phase, patients took $500 \mathrm{mg}$ of ASA every $12 \mathrm{~h}$ for 2 days. At this time, a second sample was taken. The samples were processed, and the parameters as above were assessed. Patients were asked to answer the questionnaire again. The adverse effects were registered and investigation proceedings were carried out by the psychiatry service medical staff at INNN, who had no information about the patients' treatment. These professionals were well qualified to evaluate the described adverse effects.

The degree of binding in patients before the coadministration was $84.4 \pm 7.07 \%$, and after its administration with the second drug, it was $72.18 \pm 6.5 \%(p<$ .05 , Student's $t$-test). The protein levels in all patients were normal. The study confirms that imipramine has a high degree of binding to plasma proteins (Kristensen 1983). When patients were treated with imipramine only, they reported 18 different adverse effects; whereas, after adding the salicylate, the number of adverse effects increased to 28. A parameter confirming the presence of a greater amount of free drug, after the interaction process, was the change in the severity of adverse effects. When patients were treated with imipramine only, 39 effects were expressed as mild, 30 as moderate, and 12 as severe. After the administration of the salicylate, 62 effects were recorded as mild, 31 moderate, and 30 as severe, as shown in Figure 1. No significant increments were seen in the effects classified as moderate. However, in those cases of mild and severe adverse effects, there was a significant increment $(p<.05$, Student's $t$-test) after administrating the combined drugs. During the analysis of the adverse effects, we found 15 adverse effects that may be common to the levels of imipramine (Petit et al. 1977). However, these effects were found to increase in severity when the amount of free drug increased. The imipramine binding process to plasma proteins may be affected, as in this case, by salicylates as precedent, and studies seem to confirm this process.

Hugo Juárez-Olguín, M.Sc. Helgi Jung-Cook, Ph.D. Janett Flores-Pérez, M.Sc. Ismael Lares-Asseff, M.D., Ph.D. Unidad de Farmacología Clínica, INP Departamento de Farmacología, Facultad de Medicina, UNAM 


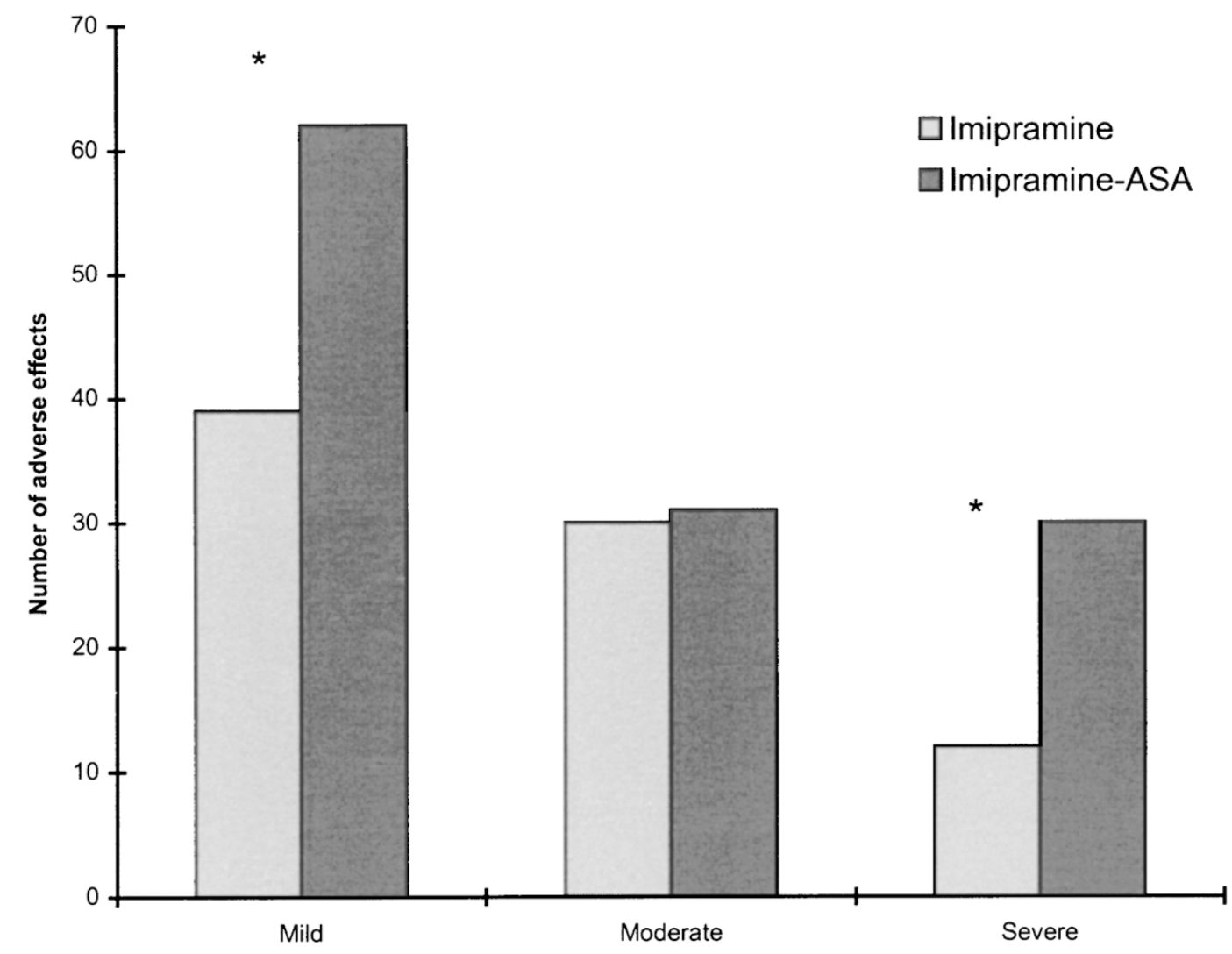

Figure 1. Severity of adverse effects produced by imipramine in depressed patients before and after adding the second drug; ${ }^{*}(p<.05$, Student's $t$-test $)$

Departamento de Neurofarmacología, INNN Mexico City, MEXICO

\section{REFERENCES}

Demyttenaere K (1997): Compliance during treatment with antidepressants. J Affect Disord 43:27-39

Fincke BG, Miller DR, Spiro A (1998): The interaction of patient perception of overmedication with drug compliance and side effects. J Gen Intern Med 13:182-185

Juárez H, Jung H (1986): Unión de imipramina a proteínas plasmáticas utilizando un método de diálisis al equilibrio. Arch Neurosc 1:46-47

Kristensen CB (1983): Imipramine serum protein binding in healthy subjets. Clin Pharmacol Ther 34:659-694

Petit JM, Spiker DG, Rutwitch JF (1977): Tricyclic antidepressant plasma levels and adverse effects after overdose. Clin Pharmacol Ther 21:47-51 